\title{
Length ratio, histological structure, feed composition, and enzyme activity in the gut of yellow rasbora (Rasbora lateristriata Blkr.)
}

\author{
Untung Susilo ${ }^{1, *}$, Purnama Sukardi ${ }^{2}$, Ridwan Affandi ${ }^{3}$ \\ ${ }^{1}$ Faculty of Biology, Jenderal Soedirman University, Purwokerto, Indonesia \\ ${ }^{2}$ Faculty of Fisheries and Marine Science, Jenderal Soedirman University, Purwokerto, Indonesia \\ ${ }^{3}$ Faculty of Fisheries and Marine Science, Bogor Agricultural University, Bogor, Indonesia
}

\begin{abstract}
A study of the ratio of gut length, histological structure, feed composition, and enzyme activity in the foregut had carried out to determine the feed category of yellow rasbora. The study used a survey method with sampling in the Banjaran River, Banyumas, Central Java. The research data had analyzed quantitatively and descriptively. The results showed that the gut length ratio of yellow rasbora ranged from 0.53 to 0.81 . Gut histological showed no stomach structure with the relative height of the villi in the middle intestine approaching 0.5 . Feed composition in the foregut showed that $60 \%$ was animal, and the rest were detritus and microalgae. Measurement of protease activity at foregut showed that no acidic protease activity but found alkaline proteases. In conclusion, yellow rasbora was an omnivorous fish with a short intestine and no functioning stomach.
\end{abstract}

\section{Introduction}

Fish based on their main diet are classified as herbivores whose main diet is plants, omnivores whose main diet is a mixture of plant and animal feed, and carnivores whose main diet is animal feed. Herbivorous fish generally have a larger ratio of gut length to body length than fish with higher trophic levels [1]. Omnivorous fish have a gut length ratio to body length in an intermediate position, as found in gobies Amblygobius phalaena and Valenciennea sexguttata have a ratio of the intestine to body length of 1.3-2.1 and 1.151.54 [2]. The carnivorous fish generally have a ratio of gut length to body length less than one as in the Gobi fish Cryptocentrus cinctus, which has a short intestine (ratio 0.73-0.96), and Eleotris sandwicensis has a short intestine (small ratio) [1,2]. However, the correlation between relative gut length and body length is inconsistent with the level trophic category. In Puntius stoliczkanus (Cyprinidae) has an intestine length in the intermediate position with a relative gut length of $1.93 \pm 0.21$ ( 2 times body length) and was grouped as a herbivorous fish [3], Austrolethops wardi has an intestine ratio of 0.77- 1.17 was also included in the herbivore group [2].

\footnotetext{
* Corresponding author: untung.susilo@unsoed.ac.id
} 
The ratio of gut length to body length of fish can change with changes in body size and diet. In Hoplias malabaricus (Erythrinidae), fish that experienced growth inhibition due to fasting caused a decrease in intestinal length and pyloric thickness but refeeding resulted in a longer intestine than fish that did not fast, an indication of growth compensation [4]. The increase in juvenile growth of Clarias gariepinus fish fed with plant-based diets also resulted in changes in the intestinal structure in the length and width of the intestinal villi [5].

The category of fish based on relative gut length is also not always consistent with the feed found in the digestive tract. Eleotris sandwicensis consumed 56.2\% animal feed and $43.7 \%$ plant food in carnivorous fish with short intestines. In contrast, fish with relatively long intestines in the intermediate position (omnivores), such as Lentipes concolor and Stenogobius hawaiiensis, more than $90 \%$ of the intestinal contents vegetable feed [6]. However, the catfish, Synodontis nigrita, which has an intestine length of three times the body length and belongs to the omnivore group, was mainly phytoplankton, zooplankton, detritus, plant tissue, insects, crustaceans, and insect parts [7]. Cyprinus carpio var. specularis (omnivorous) which has a relative intestinal length of 2.66 , in its stomach $(1 / 3$ of the foregut) found aquatic plants $(20.12 \%)$, phytoplankton $(16.46 \%)$, zooplankton $(19.69$ $\%$ ), detritus (22\%), insects (6.7\%) and semi-digested material (14.83\%) [8]. Fish with different feed categories based on relative gut length were not always in harmony with their consumed feed. Whether this pattern is also found in yellow rasbora, a study is needed to understand the initial study of their feed needs.

The yellow rasbora, Rasbora lateristriata Blkr., is a small and wild fish but has good taste, so it is in demand. Therefore, it is interesting to study its biological character further. Preliminary studies on the genus Rasbora have been carried out, including those related to the study of morphology and feeding habits [9,10]. Early studies on yellow rasbora had carried out regarding the activity of digestive enzymes $[11,12]$. However, studies related to the ratio of gut length, intestinal histological structure, feed composition, and protease activity of the foregut had not been carried out on yellow rasbora

The purpose of this study was to determine the ratio of intestinal length, intestinal histological structure, feed composition, and foregut protease activity to determine the category of yellow rasbora based on their diet. The results of this study are expected to provide more comprehensive information about the feed category of yellow rasbora.

\section{Methods}

The research was conducted by survey method with sampling at one location. Test fish samples were obtained from catches in the Banjaran River, Purwokerto, Banyumas at coordinates $109^{0} 13^{\prime} 24,497^{\prime \prime} \mathrm{E}$ and $-7^{0} 25^{\prime} 7.215^{\prime \prime} \mathrm{S}$ with a fishing area of approximately 500 meters. The fishing nets had used to capture the fish sample. The fish used in this study had a body length ranging from $3-10 \mathrm{~cm}$. The fish obtained were then used to measure the ratio of gut length, gut histology, feed composition in the intestine, and pepsin-like activity of the foregut. The number of fish samples used in this study was 166 fish to calculate the relative gut length, 20 fish to observe the feed composition in the foregut (pseudo stomach), one fish to make intestinal histological preparations, and 20 fish to test the protease activity in the foregut.

\subsection{Relative gut length (RGL)}

Fish samples were brought to the Animal Physiology Laboratory, Faculty of Biology, Jenderal Soedirman University, and preserved with 5\% formalin. The total body length and intestine were measured with a ruler with an accuracy of $1 \mathrm{~mm}$. Intestines or guts measured 
from the posterior of the stomach to the anus [1]. The body length and intestine data were used to calculate the relative gut length, which was the ratio of gut length to total body length. The relative gut length obtained was then analyzed using analysis of variance.

\subsection{Histological structure of the gut}

Observation of the histological structure of the digestive tract of yellow rasbora was carried out with Periodic Acid Schiff (PAS) staining. The fish samples were selected as adult fish with a bodyweight of $3.9 \mathrm{~g}$ and a total length of $7.8 \mathrm{~cm}$. They already had a digestive tract large enough to make histological preparations. The histological preparations were analyzed descriptively, and the villi height and gut diameter were measured. The villi height and intestinal diameter were used to calculate the ratio of villi to intestinal diameter. The gut areas sampled for the preparation of histology preparations are shown in Fig.1.

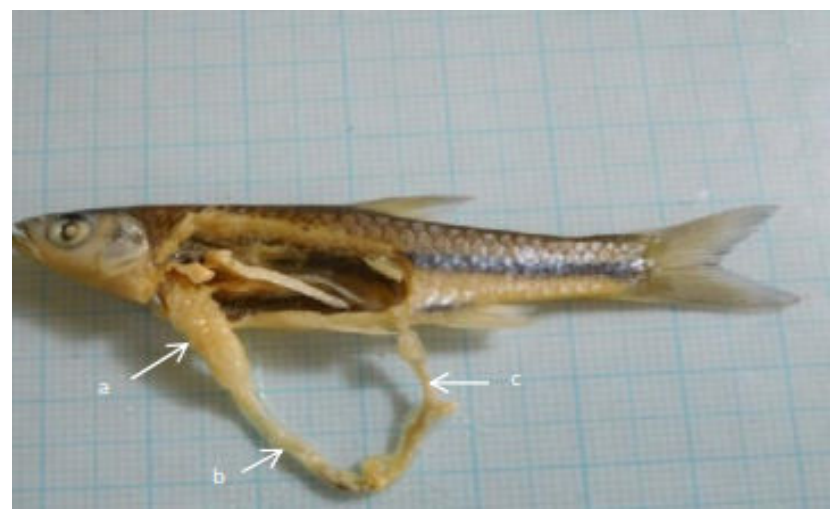

Fig. 1. The gut area was sampled for histological preparations. a. foregut, b. midgut, c. Hindgut.

\subsection{Food composition in the foregut}

Analysis of the foregut contents was carried out with the help of a loupe and a microscope. The foregut or stomach content was calculated and identified with a microscope. The number of fish used for observing the composition of the feed was 20 individuals with a total length of $5.27 \pm 0.34 \mathrm{~cm}$. The number and volume of the type of feed in the foregut were calculated from three microscopic fields of view. Index of Preponderance of the largest index used to analyze the frequency and volume of types of food contained in the foregut of yellow rasbora. Index of Preponderance was calculated based on the following formula [13]:

$$
\mathbf{I P}=[(\mathrm{Vi} \times \mathrm{Oi}) / \Sigma \text { Vi x Oi }] \times 100
$$

IP is Index of Preponderance, $\mathrm{Vi}$ is the percentage of the volume of one type of feed, Oi is the percentage of frequency of occurrence of one type of feed, $\Sigma \mathrm{Vi} \mathrm{xOi}$ is the sum of VixOi of all types of feed

\subsection{Protease activity in the foregut}

The foregut or pseudo-stomach of the fish was isolated and crushed with an electric homogenizer in a cold buffer solution of $10 \mathrm{mM} \mathrm{HCl} \mathrm{pH} 2.0$ and $50 \mathrm{mM}$ Tris-HCl $\mathrm{pH} 7.6$ with a ratio of $1: 8(\mathrm{w}: \mathrm{v})$. Buffer solution of $10 \mathrm{mM} \mathrm{HCl} \mathrm{pH} 2.0$ was used to obtain a crude extract of the enzyme to measure acid protease activity (pepsin-like). While buffer solution of $50 \mathrm{mM}$ Tris- $\mathrm{HCl} \mathrm{pH} 7.6$ was used to get a crude enzyme to measure alkaline protease 
activity. The homogenate was centrifuged at a speed of $12000 \mathrm{rpm}$ (temperature $4^{0} \mathrm{C}$ ) for 15 minutes. The supernatant was collected in an Eppendorf tube and stored in a $-80^{\circ} \mathrm{C}$ freezer until used. Measurement of acid protease (pepsin-like) activity using a buffer of 60 $\mathrm{mM} \mathrm{HCl} \mathrm{pH} 2.0$ following the casein hydrolysis method [14]. Measurement of alkaline protease activity using $0.1 \mathrm{M}$ Tris- $\mathrm{HCl}$ buffer $\mathrm{pH} 8.0$ with casein as the substrate [15]. The protease activity was calculated from the absorbance of the sample minus the blank divided by the incubation time (minutes) and the volume of enzyme extract $(\mathrm{ml})$. The protease activity was expressed in units of Abs..minute ${ }^{-1} \cdot \mathrm{ml}^{-1}$.

\section{Results}

The calculation of the relative gut length of the yellow rasbora with a sample of 166 individuals showed that the yellow rasbora measured in the body length range of $3.0-10.9$ $\mathrm{cm}$ had a relative gut length ranging from 0.53 to 0.81 (Fig. 2.). Analysis of variance showed a significant difference between different fish size groups $(\mathrm{P}<0.05)$.

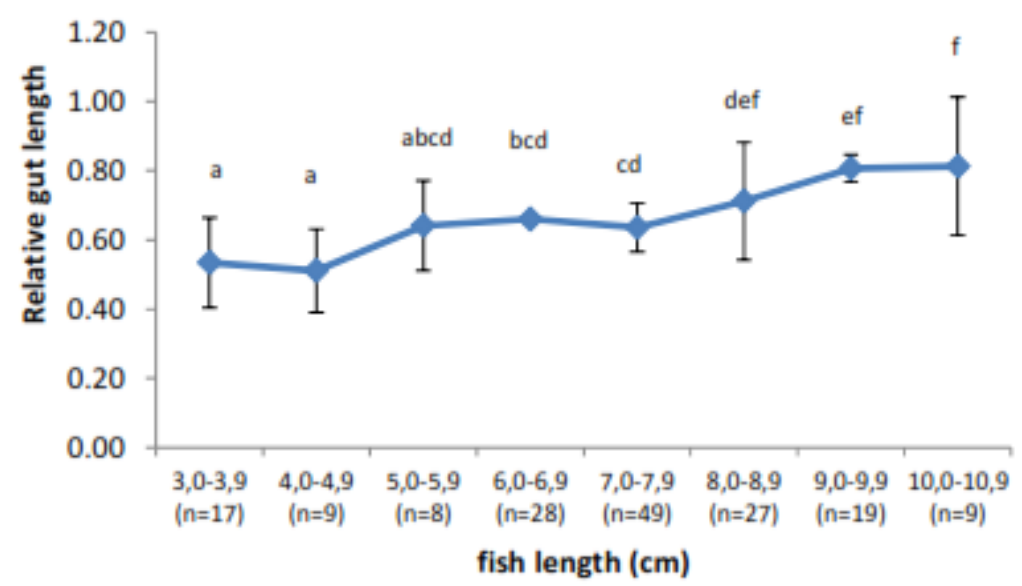

Fig. 2. Relative gut length of yellow rasbora. Different letters showed significant differences $(\mathrm{P}<0.05)$.

Histological staining of the intestine using PAS (Periodic Acid Schiff) stain showed the same pattern on the surface of the digestive tract, which was pink or red-orange (Fig. 3. af). Short villi were found in the foregut or stomach (Fig. 3.a), but high and touching villi were found in the mid-gut and hindgut (Fig. 3.b \& c). 

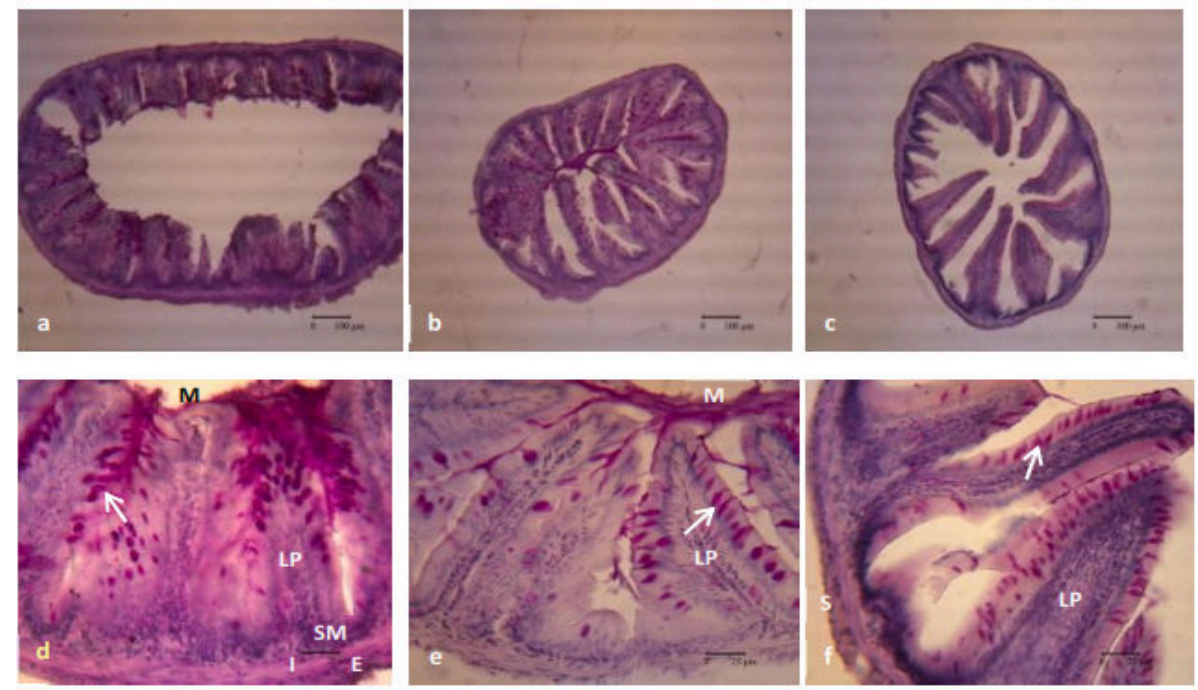

Fig. 3. Histological structure of the gut of yellow rasbora (PAS at magnification 10x (a-e) and 40x (fj) objective).

Description: a,d. The foregut; b,e. midgut; c,f. hindgut. M. Mucosa, LP: Lamina propia, $\boldsymbol{\nearrow}$ Goblet cells, I. Internal muscle layer, E. External muscle layer, S. Serosa, SM. Sub muscularis

The results of the calculation of the average relative height of the villi, namely the ratio of villi height to the diameter of the digestive tract of yellow rasbora were listed in Table 1. The relative villi height calculation results indicate an increase in relative villi height, especially marked by the relative villi height found in the mid and hindgut (Table 1.). The relative height of the villi in the foregut, which was only around 0.290 , was thought that this area was not the primary site of nutrient absorption. The relative height of the villi in the mid and hindgut did not differ from that found in Epinephelus coioides, but different to Rastrelliger brachysoma (Table 1).

Table 1. The relative gut villi height of the yellow rasbora compared to other species.

\begin{tabular}{|l|c|c|c|}
\hline Species & Foregut & Midgut & Hindgut \\
\hline Rasbora lateristrata & 0.290 & 0.499 & 0.472 \\
\hline Rastrelliger brachysoma [3] & - & 0.266 & 0.213 \\
\hline Epeniphelus coioides [16] & - & 0.471 & - \\
\hline
\end{tabular}

The diameter of the foregut or stomach was small, which was around $3 \mathrm{~mm}$. It will be complicated to identify the type of feed that was intact in the stomach contents. From a total of 60 individuals caught, only 20 were found whose stomachs contained food. Due to the small size of the foregut or stomach, the gastric's contents observation contents were carried out with the aid of a microscope. The results of the calculation of the preponderance index show that there was a tendency for yellow rasbora to like animal feed by $60 \%$ (18\% cut of animals, $21 \%$ worms, and $21 \%$ fish) and $38 \%$ detritus. In comparison, microalgae only found with a small proportion of $2 \%$ ( Fig. 4.). 


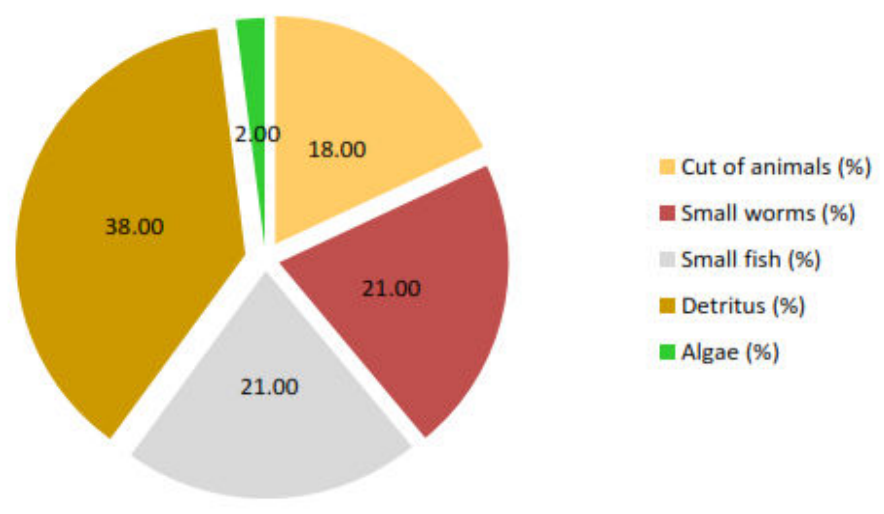

Fig. 4. Composition of the natural diet of yellow rasbora.

The results of the protease activity of the foregut or stomach, which were measured as absorbance values, showed no acid protease or pepsin-like activity but showed the presence of alkaline protease activity (Fig. 5).

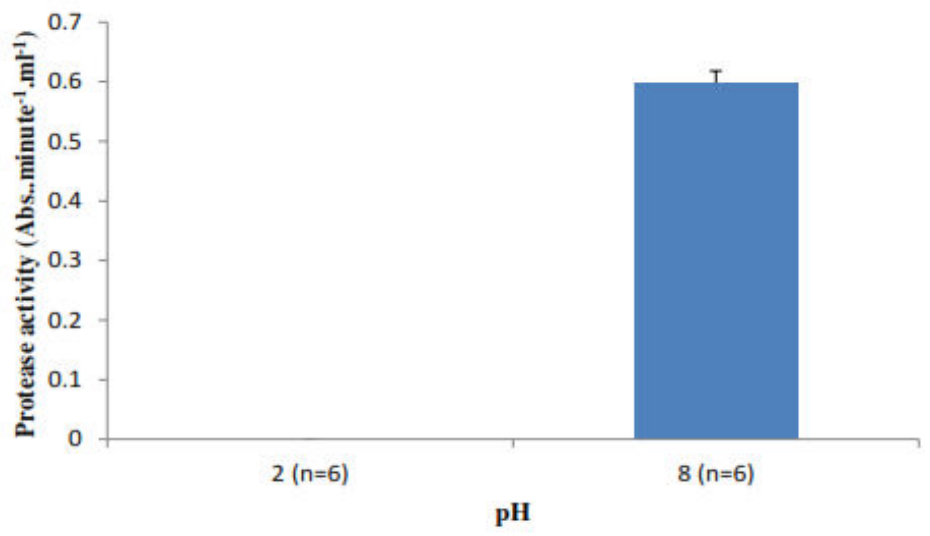

Fig 5. Protease activity in the foregut of yellow rasbora.

\section{Discussion}

Different fish categories based on their diet can be evaluated by their relative gut length or gut length ratio. The relative gut length is the ratio between the length of the intestine and the total length of the fish. Herbivorous fish generally have a larger relative gut length (RGL) than omnivorous and carnivorous fish. Previous studies have shown that algaeeating Atherinops affinis has an RGL of 1.5 [17], marine herbivores have an RGL of 1.617.75 [18,19], Scortum ogilbyl and Scortum parviceps have an RGL of 3. 6-17.6 [20]. Carnivorous fish generally have a lower RGL than herbivorous fish. Previous studies have shown that Glyptosternum maculatum has an RGL of 0.898 [21], carnivorous fish with a preference for fish, and Cephalopada and Decapoda have an RGL of 0.47-0.65 [19]. In this study yellow rasbora had RGL ranging from 0.53 to 0.81 (Fig. 2.).

The results of this RGL study indicate that yellow rasbora had a short intestine, as found in carnivorous fish. Sill because it does not have a perfect stomach, there was no pepsin- 
like activity, and the food composition in the foregut was a mixture of animal vegetables. (Fig. 4), the yellow rasbora was classified as an omnivorous fish. The RGL value of yellow rasbora in this study also seems to have changed significantly (Fig. 2.). Changes or differences in gut length, which have implications for RGL values, appear to be related to omnivorous fish with changes in the composition of the feed obtained. In general, fish that consume a lot of animal feed will have a lower RGL value than fish that consume a lot of plant food, as shown in Atherinops affinis (algae eater), which has a higher RGL value than Leuresthes tenuis (animal eater) [21]. Studies on silver-carp, Hypophthalmichthys molitrix, had also shown changes in RGL values when there was a change in the composition of the zooplankton diet [22].

The perfect stomach of fish has a histological structure consisting of mucosa with villi, gastric glands, lamina propria, gastric pit and an internal muscular layer found in Himantura signifier, Epinephelus coioides, Rastrelliger brachysoma and Trachelyopterus striatulus $[3,15,22,23]$. The histological structure of the fish gut was composed of villous mucosa, goblet cells, lamina propria, submucosa, internal and longitudinal muscular layers [24,25]. The results of histological observations of the foregut of yellow rasbora also showed the presence of villous mucosa with goblet cells and lamina propia (Fig. 3). The PAS stain used was also positive, indicating the presence of neutral polysaccharide mucus. PAS staining of the midgut was also positive, composed of villous mucosa, and complemented by goblet cells in both the mid and hind intestines. The intestines show high villous folds, especially the middle and posterior intestines (Fig. 3.d,e). The results of this histological observation are the justification for the absence of a perfect stomach in yellow rasbora.

The measurement of the ratio of villi to gut diameter also showed a ratio of villi in the mid and hindgut ranging from 0.472 to 0.499 , which was not different from that of Epinephelus coiodes, but larger than Rastrelliger brachysoma (Table 1.). The high ratio of villi in the intestine was an indication that the middle and hind intestines of yellow rasbora were not different from carnivorous fish. Still, yellow rasbora was more appropriately classified as omnivorous fish due to the absence of a perfect stomach. The presence of pepsin activity was an indication of a functional stomach. In this study, no pepsin-like activity was found in the foregut of yellow rasbora. This condition was different from Sparus aurata [26], Oreochromis niloticus, Parachana obscura, and Gymnarchus niloticus [27], Polydon spathula [28], and Chelon labrosus [29], which have pepsin activity in the stomach. So the high villi intestine (Table 1; Fig. 3) was more due to an adaptation to the short intestines of yellow rasbora to maximize the absorption of nutrients from the digestive process. The presence of high villous folds to compensate for the short digestive tract was also found in Trachelyopterus striatulus [23].

The feed category of yellow rasbora as omnivorous fish was also supported by analysing the feed composition in the foregut which was different from that found in carnivorous fish. Carnivorous fish generally like animal food in the form of fish or invertebrate prey. Previous studies have shown the fish Atherinops affinis and Leurethes tenuis, whose gut contents were dominated by animal feed [17] and what happened to Synbranchus marmoratus with gut contents in the form of crustaceans [30]. In line with previous studies, the contents of the foregut of yellow rasbora in this study consisted of animal derivatives, worms, small fish, detritus or unidentified material, and microalgae (Fig. 4.). The results of this study were not different from previous studies on Rasbora argyrotaenia whose gut contents also contained insects, microscopic crustaceans, rotifers, detritus and algae [10]. Still, under acidic environmental conditions, the intestinal contents of Rasbora argyrotaenia could be dominated by Bracillariophyceae [31]. So it seems that yellow rasbora can group as omnivores with carnivorous tendencies. 


\section{Conclusion}

The yellow rasbora was omnivorous fish with the characteristics of a short intestine, not having a perfect stomach, had a middle and hindgut with high villous folds, and likes animal feed and detritus. Determination of yellow rasbora through a comprehensive study carried out in this study was also one of the novelties of this research.

\section{Acknowledgments}

We want to express our gratitude to the Ministry of Research, Technology and Higher Education of the Republic of Indonesia, which has assisted in funding through the Doctoral Dissertation Research Grant for 2016, so the research was completed.

\section{References}

1. C.E. Wagner, P.B. McIntyre, K.S. Buels, D.M. Gilbert, E. Michel, Func. Eco. 23, 6 (2009)

2. C. Pogoreutz, H. Ahnelt, J. of App. Ichthyol. 30, 2 (2014)

3. M.H. Kido, Pasific Sci. 50, 2 (1996)

4. S. Senarat, W. Yenchum, P. Poolprasert, Kasetsart, J. Nat. Sci. 47, 247-251 (2013)

5. F.S. Rios, A.L. Kalinin, M.N. Fernandes, F.T. Rantin, Brazilian J. of Bio. 64, 683689 (2004)

6. O. S. Bello, B. O. Emikpe, Int. J. Morphol. 30, 1 (2012)

7. B.A. Shinkafi, L.A. Argungu, H.S. Akanbi, Nigerian J. of Basic and App. Sci. 18, 2 (2010)

8. M.R. Manon, M.D. Hossain, J of Sci. Foundation, 9, 163-169 (2011)

9. R. Dina, M. Boer, N.A.Butet, Oce. \& Limnol. Di Ind. 37, 1 (2011)

10. B. Sulistiyarto, J. of Trop. An. Sci. 1, 2 (2012)

11. U. Susilo, P. Sukardi, R. Affandi, Molekul 11, 2 (2016)

12. U. Susilo, P. Sukardi, R. Affandi, Molekul 13, 1 (2018)

13. A.V. Natarajan, A.G. Jhingran, Indian J. of Fish. 8, 1 (1961)

14. K. Rungruangsak, F. Utne, Aqu. 22, 67-79 (1981)

15. V.V. Kuz'mina, G.V. Zolotareva, V.A. Sheptitskii, J. of Ichthyol. 56, 1 (2016)

16. S. M. Banan Khojasteh, S. Ghodratiniya, Int. J. of Aq Sci. 4, 2 (2013)

17. M.H. Horn, A.K. Gawlicka, D.P. German, E.A. Logothetis, J.W. Cavanagh, K.S. Boyle, Mar. Biol. 149, 5 (2006)

18. P.K. Karachle, K.I. Stergiou, Mar. Biodiver Rec. 3, 1-10 (2010)

19. P.K. Karachle, K.I. Stergiou, Acta Ichthyol. et Piscatoria 40, 2 (2010)

20. D.M. Xiong, C.X. Xie, H.J. Zhang, H.P. J. of An. Phys. and An. Nut. 95, 1 (2011)

21. Z. Ke, P. Xie, L. Guo, The Sci. World J. 8, 169-175 (2008)

22. K. Chatchavalvanich, R. Marcos, J. Poonpirom, A.Thongpan, E. Rocha, An. and Embrio 211, 5 (2006)

23. M.L.D. Santos, F.P. Arantes, T.C. Pessali, J.E.D. Santos, Zoo. (Curitiba) 32, 4 (2015)

24. M. Nazlić, A. Paladin, I. Bočina, Acta Adriatica 55, 1 (2014) 
25. L. Yang, J. Fang, X. Peng, H. Cui, M. He, Z. Zuo, Z. Yang, Fish Phys. and Biochem. 43, 4 (2017)

26. S. Deguara, K. Jauncey, C. J. of Fish Biol. 62, 5 (2003)

27. O. Fagbenro, O. Adedire, O. Fateru, I. Oluwabukola, O. Ogunlana, B. Akanbi, P. Ayo-Amu, An. Res. Inter. 2, 2 (2005)

28. H. Ji, H.T. Sun, D.M. Xiong, Fish Phys. \& Biochem. 38, 3 (2012)

29. I.M. Pujante, M. Díaz-López, J.M. Mancera, F.J. Moyano, Aqua. Res. 48, 2 (2017)

30. L.A. Montenegro, N.B. da Silva, W.S. do Nascimento, S. Chellappa, An. Biol. J. 3, 3 (2012)

31. B. Sulistiyarto, J. of Trop. An. Sci. 2, 1 (2013) 